\title{
Fuzzy Cognitive Map to Analyze the Impact of Modern Technology on Bangladeshi Handloom Weavers
}

\author{
Md. Ashraful Alam \\ Dept. of Mathematics \\ Jahangirnagar University \\ Bangladesh
}

\author{
Satrajit Kumar Saha \\ Dept. of Mathematics \\ Jahangirnagar University \\ Bangladesh
}

\author{
Nirmal Kanti Mitra \\ Dept. of Mathematics \\ BUBT \\ Bangladesh
}

\begin{abstract}
Handloom industry in Bangladesh is having glorious past, questionable present and blurry future due to a lot of internal and external factors that are acting behind the scene [12]. This ancient and most important cottage industry of Bangladesh is now on the way of extinction because of various problems and barriers adjacent to this industry. Fuzzy Cognitive Maps (FCM) have been applied in many fields successfully to show the causes and effect relationship. In this research work, the socio economic problems faced by the Handloom weavers has been analyzed with the help of FCM. FCM is a fuzzygraph modeling approach based on expert's opinion. This is the non-statistical approach to study the problems with imprecise information This paper has five sections. Section one gives the introduction, Section two talk about the motivation, the literature survey of fuzzy cognitive maps (FCM), are given in Section three, Section four presents the adaption and implementation of FCM to the problem, Final section derives the conclusion based on study. Actually, this work is an extension of Md. Ashraful Alam et el (2016) [1].
\end{abstract}

\section{Keywords}

Handloom industry in Bangladesh, Fuzzy Cognitive Maps (FCM)

\section{INTRODUCTION}

In 1976, Political scientist R. Axelord has introduced a model called Cognitive Maps (CM) [3] to study decision making in social and political systems. $\mathrm{CM}$ is digraph designed to represent the causal assertion and belief system of a person (or group of experts) with respect to a specipic domain and uses that statement in order to analyze the effect of a certain choice on a particular objective. Fuzzy Cognitive Map (FCM), introduced by Bart Kosko in 1986 [3], extends the idea of CM by allowing the concepts to be represented linguistically with an associated fuzzy set. FCM can successfully represent knowledge and human experience, introduced concept to represent the essential elements and the cause and effect relationships among the concepts to model the behavior of any system. It is very convenient, simple and powerful tool, which is used in numerous fields social, economical and medical etc. In this work, the notion of Fuzzy Cognitive Maps (FCM) has been recalled, which was introduced by Bart Kosko.

\section{MOTIVATION}

Handloom sector in Bangladesh consists of more than 0.183 million handloom units with 0.505 million handlooms and about 1 million handloom weavers of which about $50 \%$ are female worker. This ancient and most important cottage industry of Bangladesh is now on the way of extinction because of various problems and barriers adjacent to this industry. Prof. (Dr.) Kuldeep Singh and Dr. Monica Bansal in their paper have discussed about the handloom export units in
India. They say, handloom sector plays a very important role in India's economy. As a result of effective Government intervention through financial assistance and implementation of various developmental and welfare schemes, this sector has been able to withstand competition from the power loom and mill sectors. The writing of Nuimuddin Chowdhury [4], discusses the Bangladesh's handloom economy in transition. $\mathrm{He}$ cased of unequal growth structural adjustment and economic mobility amid laissez-faire markets. Banarjee et al. [2], tried to identify the causes of weaver migration from Bangladesh to India. They identified the factors like fear of communal violence, increased price of raw materials, absence of loan from government, insufficient transport facility, better facilities in India, lack of security for their rapid migration to India. Jaforulla [10] estimated the technical efficiency of handloom weaving industry in Bangladesh. He showed that technical efficiency of handloom industry of Bangladesh is only $41 \%$ and its technical efficiency might be improved by increasing its male and female labor ratio and decreasing its hired/family labor ratio and labor-capital ratio. Rahman [13] analyzed the prospects of handloom weaving industry in Pabna district of Bangladesh. The study identified all the internal and external factors that help to understand the present condition of the handloom industry operating in Pabna district. The study found that shortage of working capital, high cost of raw materials, lack of organizing capability, inadequate technology and efficiency, lack of policy support, huge knowledge gap, lack of power supply and shortage of credit facilities are the main features of the handloom units operating in Pabna district of Bangladesh. Islam et al. [8] analyzed the cost and benefit of handloom weaving units operating in Kumarkhali Upazila of Kushtia District. The cost-benefit analysis found that handloom weaving activity is profitable and profit per-loom for small scale and large scale units are higher than that of the medium scale units. Ghosh and Akter [7], in their research have identified those predominant factors that are moving the wheels of this industry slowly. They have found that shortage of working capital, high cost of raw material procurement, lack of organizing capability, inadequate technology and efficiency, and lack of policy support are major forces which are bitterly hit the handloom industry. Islam and Hossain [9] analyzed the technical inefficiency of handloom industry. They have found that education, experience, size of units, and age of owners are significant factors inflowing technical inefficiency of handloom industry. Vasantha Kandasamy, W.B. and F. Smarandache [3] have worked on Fuzzy Relational Equations to study the problems of Indian silk weavers. However, to the best of our knowledge none of the earlier studies analyzed (mathematically) the challenges in handloom industry in the case of Bangladesh. So, this study will try to establish a mathematical way based on FCM to identify the challenges and recommend some ideas that can help in flourishing handloom industry in Bangladesh. The objective of 
this work is twofold. Firstly, the problems of Bangladeshi weavers has been studied through existing works and by collecting data from the field. Secondly, this paper has recommended some ideas to overcome from that situation.

\section{FUZZY COGNITIVE MAPs (FCM)}

\subsection{Preliminaries}

Fuzzy Cognitive Maps (FCM) are more applicable when the data in the first place is an unsupervised one. It model the world as a collection of classes and causal relations between classes. Here, we introduced some basic definitions of FCM as follows:

\subsubsection{Definition[5],[6],[15]}

A FCM is a directed graph with concepts like polices, events etc, as nodes and causalities as edges. It represent causal relationship between concepts. If increses (or decreses) in one concept/ node leads to increase (or decrease) in another concept, we give the value 1 ; otherwise we give the value -1 . If there exists no relation between concepts the value 0 is given. Let $C_{1}, C_{2}, \ldots \ldots \ldots, C_{n}$ be the nodes of the FCM. Suppose that the directed graph is drawn using weights $e_{i j} \in\{0,1,-1\}$. The matrix $E$ is defined by $E=\left(e_{i j}\right)$; where $e_{i j}$ is the weight of the directed edge $C_{i} C_{j} . E$ is called the adjacency matrix of the FCM. All matrices associated with an FCM are always square matrices with diagonal entries equal to zero.

\subsubsection{Definition [6],[15]}

Let $C_{1}, C_{2}, \ldots \ldots \ldots, C_{n}$ be the nodes of the FCM. Let $A=\left\{a_{1}\right.$, $\left.a_{2}, \ldots \ldots \ldots, a_{n}\right\}$, where $a_{i} \in\{0,1\} . \quad \mathrm{A}$ is called the instantaneous state neutrosophic vector and it denotes the $\mathrm{ON}-\mathrm{OFF}$ state position of the node at an instant

$$
a_{i}=\left\{\begin{array}{l}
0 \text { if } a_{i} \text { is OFF (no effect) } \\
1 \text { if } a_{i} \text { is ON (has effect) }
\end{array}\right.
$$

\subsubsection{Definition [6],[15]}

Let $C_{1}, C_{2}, \ldots \ldots, C_{n}$ be the nodes of the FCM. Let $\overrightarrow{C_{1} C_{2}}, \overrightarrow{C_{2} C_{3}}, \ldots \ldots, \overrightarrow{C_{l} C_{J}}$ be the edges of the FCM. Then the edges form a directed cycle. An FCM is said to be cyclic if it possesses a directed cycle. An FCM is said to be acyclic if it does not possess any directed cycle.

\subsubsection{Definition [6],[15]}

An FCM with cycle is said to have a feedback. Whe there is a feedback in the FCM i.e. when the causal relations flow through a cycle in a revolutionary manner the FCM is called a dynamical system.

\subsubsection{Definition [6],[15]}

Let $\overrightarrow{C_{1} C_{2}}, \overrightarrow{C_{2} C_{3}}, \ldots \ldots \ldots, \overrightarrow{C_{l-1} C_{l}}$ be cyclic when $C_{i}$ is switched on and if the causality flow through the edges of a cycle and if it again causes $C_{i}$, we say that the dynamical system goes round and round. This is true for any node $C_{i}$, for $i=$ $1,2, \ldots \ldots \ldots, n$, the equilibrium state for this dynamical system is called the hidden pattern.

\subsubsection{Definition [6],[15]}

If the equilibrium state of a dynamical system is a unique state vector, then it is called a fixed point. Consider the FCM with $C_{1}, C_{2}, \ldots \ldots \ldots, C_{n}$ as nodes. For example, let us start the dynamical system by switching on $C_{1}$. Assume that the FCM settles down with $C_{1}$ and $C_{n}$ ON, i.e. the state vector remain as $(1,0,0, \ldots \ldots \ldots, 1)$, this state vector is called fixed point.
3.1.6 Definition [6],[15]

If the FCM settles with a state vector repeating in the form $A_{1} \rightarrow A_{2} \rightarrow \ldots \ldots \ldots A_{i} \rightarrow A_{1}$, then the equilibrium is called a limit cycle of the FCM.

\subsubsection{Definition [5],[6],[15]}

Suppose $A=\left(a_{1}, a_{2}, \ldots \ldots \ldots, a_{n}\right)$ is a vector which is passed into a dynamical system $E$. Then $A E=\left(\dot{a}_{1}, \dot{a}_{2}, \ldots \ldots \ldots, \dot{a}_{n}\right)$, after thresholding and updating the vector, suppose we get $\left(b_{1}, b_{2}, \ldots \ldots \ldots, b_{n}\right)$.We denote that by $\left(\dot{a}_{1}, \dot{a}_{2}, \ldots \ldots \ldots, \dot{a}_{n}\right) \hookrightarrow$ $\left(b_{1}, b_{2}, \ldots \ldots \ldots, b_{n}\right)$. Thus the symbol $\hookrightarrow$ means the resultant vector has been threshold and updated.

\subsection{Algorithm in Induced Fuzzy Cognitive}

\section{Map[11], [ 14]}

The Induced Fuzzy Cognitive Map (IFCM) focuses on the algorithm of the FCM which works on unsupervised data to derive an optimistic solution. To get such optimistic solution in the problem with unsupervised data, the following steps must be followed:

Step 1: Collect the nodes for the given problem, which is unsupervised data.

Step 2: Draw the directed graph for the model.

Step 3: From the FCM, obtain the connection matrix $E$. In this matrix the number of rows equal to the number of steps to be performed.

Step 4: Consider the state vector $V\left(k_{1}\right)$ by setting the first component of this vector $C_{1}$ in $\mathrm{ON}$ position and the rest of the components in the OFF position.

Step 5: Calculate $M=C_{1} \times E$. At each stage the state vector is updated and threshold. The symbol $\hookrightarrow$ represent the threshold value for the product of the result. The threshold value is calculated from $M$ by assigning the value 1 when $x_{i}>0$ and 0 when $x_{i}<0$.

Step 6: Each component in the $C_{1}$ vector is taken separately and the product of the given matrix is calculated. Find out the vector $y_{1}$, which has the maximum number of one's (1).

Step 7: Considered as fixed point when the same threshold value occurs twice and the iteration gets terminated.

Step 8: Set the vector $C_{2}$ in $\mathrm{ON}$ state and the rest of the components in OFF state. Continue the calculation discussed in steps 4 to 7.Step 9: Continue the above process for all the remaining state vector $C_{n}$ and find out the hidden pattern.

\section{ADAPTATION AND IMPLEMENTATION OF FCM TO THE PROBLEM}

Here the illustration of the dynamical system for the weavers problem is a very simple model. At the very first stage, the following seven arbitrary attributes $\left(B_{1}, B_{2}, B_{3}, \ldots \ldots \ldots, B_{7}\right)$ has been taken. It is not a hard and first rule that someone need to consider only these seven attributes. One can increase or decrease the number of attributes according to needs. The following attributes related to the labors are taken as the main nodes for study:

$B_{1}=$ No Knowledge of other works
$B_{2}=$ Advent of modern technology
$B_{3}=$ Salary they earn in a month
$B_{4}=$ Level of savings
$B_{5}=$ Level of debts

$B_{2}=$ Advent of modern technology

$B_{4}=$ Level of savings

$B_{5}=$ Level of debts 
$B_{6}=$ No interferes of Governments

$B_{7}=$ Hours of works

The Directed Graph for this case is as follows:

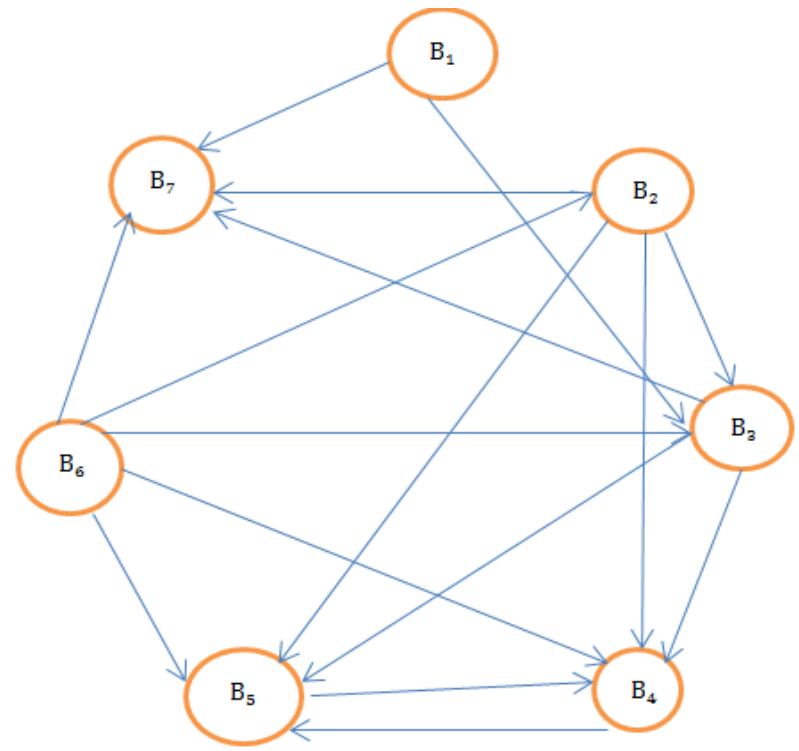

Fig-1: Directed Graph for weavers

The connection or adjacency matrix $\mathrm{M}$ is the relation between the seven attributes as concepts, assigning values as 1 , if there is any relation and 0 , if there is no relation as follows:

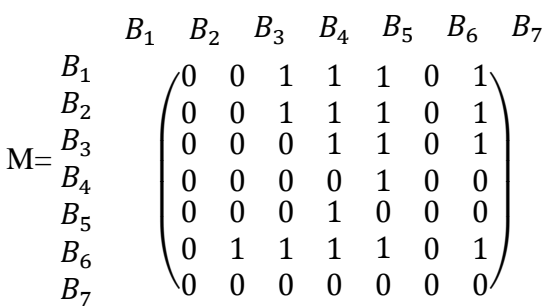

Suppose the node $C_{2}$ is in the $\mathrm{ON}$ state i.e. Advent of modern technology and all other nodes are in the OFF condition. Input the vector, $A_{1}=\left(\begin{array}{lllllll}0 & 1 & 0 & 0 & 0 & 0 & 0\end{array}\right)$

The effect of $A_{1}$ on the dynamical system $M$ is given by

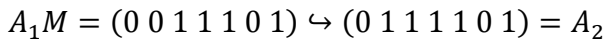
$A_{2} M=\left(\begin{array}{lllllll}0 & 0 & 1 & 3 & 2 & 0 & 2\end{array}\right) \hookrightarrow\left(\begin{array}{lllllll}0 & 1 & 1 & 1 & 1 & 0 & 1\end{array}\right)=A_{3}=A_{2}$

Where $\hookrightarrow$ denotes the thresholding and updating of the resultant state vector.

The hidden pattern is the fixed point given by $\left(\begin{array}{llllll}0 & 1 & 1 & 1 & 1 & 0\end{array}\right)$ which implies that advent of modern technology influences all other attributes except 'No Knowledge of other works' and 'No interferes of Governments'.

Again, consider the node $C_{1}$ is in the ON state i.e. No Knowledge of other works and all other nodes are in the OFF condition. Suppose the input vector

$D_{1}=\left(\begin{array}{lllllll}1 & 0 & 0 & 0 & 0 & 0 & 0\end{array}\right)$

The effect of $D_{1}$ on the dynamical system $M$ is given by

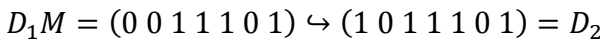

$D_{2} M=\left(\begin{array}{lllllll}0 & 0 & 1 & 3 & 3 & 0 & 2\end{array}\right) \hookrightarrow\left(\begin{array}{lllllll}1 & 0 & 1 & 1 & 1 & 0 & 1\end{array}\right)=D_{3}=D_{2}$
The hidden pattern is the fixed point given by (1 0111101$)$ which declares that three, four, five and seven attributes come to ON stage.

Again, consider the nodes $C_{6}$ is in the $\mathrm{ON}$ state i.e. No interferes of Governments and all other nodes are in the OFF condition. Suppose the input vector

$E_{1}=\left(\begin{array}{lllllll}0 & 0 & 0 & 0 & 0 & 1 & 0\end{array}\right)$

Now product of $E_{1}$ and $M$ is calculated,

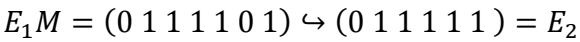

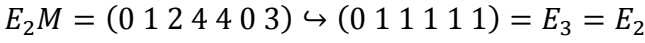

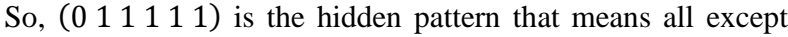
first attributes come to $\mathrm{ON}$ state.

Similarly, one can find results for other state vectors, From the above result analysis it's clear that the bonded labors standard of living is in a very pathetic condition. They don't have any other source of income or job. Their earning is bare minimum with no savings. The government doesn't come forward to help them. In their work spot, they have to slog for more than 10 hours.

This research work also observed the situation of owners of the labors. To do so, the following attributes have been considered as the main point of study.

$O_{1}=$ Advent of Modern Technology

$\mathrm{O}_{2}=$ Availability of raw materials

$\mathrm{O}_{3}=$ Demand for finished goods

$\mathrm{O}_{4}=$ Profit

$\mathrm{O}_{5}=$ Loss

The Directed Graph are as follows:

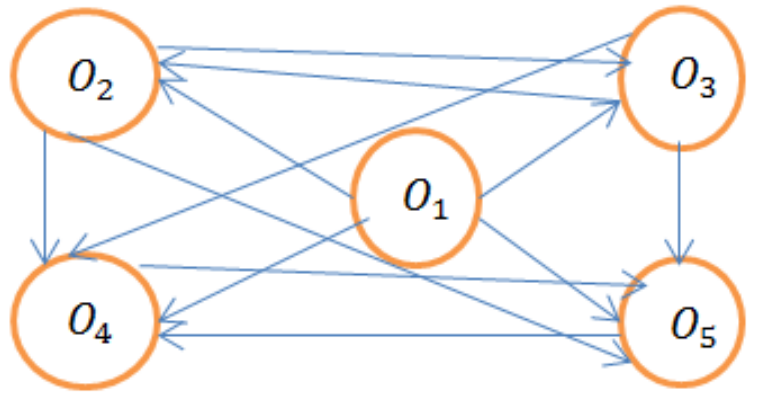

Fig-2: Directed Graph for owners of weavers

The corresponding connection matrix $M$ is as follows:

$$
\begin{aligned}
& \begin{array}{lllll}
O_{1} & O_{2} & O_{3} & O_{4} & O_{5}
\end{array} \\
& M=\begin{array}{l}
O_{1} \\
O_{2} \\
O_{3} \\
O_{4} \\
O_{5}
\end{array} \quad\left(\begin{array}{lllll}
0 & 1 & 1 & 1 & 1 \\
0 & 0 & 1 & 1 & 1 \\
0 & 1 & 0 & 1 & 1 \\
0 & 0 & 0 & 0 & 1 \\
0 & 0 & 0 & 1 & 0
\end{array}\right)
\end{aligned}
$$

Taking the node $C_{1}$ in the $\mathrm{ON}$ state i.e. Advent of Modern Technology and all other nodes are in the OFF condition, one can find the input vector as

$A_{1}=\left(\begin{array}{lllllll}1 & 0 & 0 & 0 & 0 & 0 & 0\end{array}\right)$, then

$A_{1} M=\left(\begin{array}{lllll}0 & 1 & 1 & 1 & 1\end{array}\right) \hookrightarrow\left(\begin{array}{lllll}1 & 1 & 1 & 1 & 1\end{array}\right)=A_{2}$

$A_{2} M=\left(\begin{array}{lllll}0 & 2 & 2 & 4 & 4\end{array}\right) \hookrightarrow\left(\begin{array}{lllll}1 & 1 & 1 & 1 & 1\end{array}\right)=A_{3}=A_{2}$

Again consider the node $C_{2}$ in the $\mathrm{ON}$ state i.e. Availability of raw materials and all other nodes are in the OFF condition, the input vector for this case will be 
$B_{1}=\left(\begin{array}{lllll}0 & 1 & 0 & 0 & 0\end{array}\right)$, then

$B_{1} M=\left(\begin{array}{lllll}0 & 0 & 1 & 1 & 1\end{array}\right) \hookrightarrow\left(\begin{array}{lllll}0 & 1 & 1 & 1 & 1\end{array}\right)=B_{2}$

$B_{2} M=\left(\begin{array}{lllll}0 & 1 & 1 & 3 & 3\end{array}\right) \hookrightarrow\left(\begin{array}{lllll}0 & 1 & 1 & 1 & 1\end{array}\right)=B_{3}=B_{2}$

Similarly, the results for other state vector will be obtained, all these results, shows that the owner have no profit but loss, they don't get enough raw materials to give to the bonded labors, so the demand for finished goods declines. Thus the main reason for the poverty is Modern Technology.

\section{CONCLUSION}

In this work, the major problem of the weavers and their owners have been discussed which are evolved through FCM Method. The above discussed algorithm of the given problem focused on the nodes $B_{2}$ (for weavers) and $O_{1}$ (for owners) i.e. Advent of Modern Technology which is one of the great causes for the measureable condition of the weavers.

It is high time government takes steps to revive the life of the weavers who work as bonded labourers by training and giving logistic support.

\section{ACKNOWLEDGMENTS}

The authors would like to thank the referees for providing very helpful comments and suggestions.

\section{REFERENCES}

[1] Md. Ashraful Alam, Md. Alamin Kahn, Md. Nasim Khan, Md. Babul Hossain 2016, Fuzzy Relational Equation Based on Triangular Norms to Detect the Problems of Bangladeshi weavers, Journal of Physical Sciences, Vol. 21, 37-45.

[2] Banarjee, S.; Muzib, M. M. and Sharmin, S. 2014, Status of Handloom Workers and Causes of Their Migration: A Study in Handloom Industry of Tangail District, Bangladesh, Research on Humanities and Social Sciences, Vol.4, No.22.

[3] Bart Kosko 1986. Fuzzy Cognitive Maps, International Journal of Man-machine Studies, v24, pp. 65-75.

[4] Chowdhury, N 1989, 'Bangladesh's Handloom Economy in Transition: A Case of Unequal Growth, Structural Adjustment and Economic Mobility Amid Laissez-Fair Markets: A Synthesis ', Special Issue on The Handloom Economy of Bangladesh in Transition, vol XVII, no. 1 \& 2, pp. 1-22.

[5] Craiger,J.and Coovert,M.D. 1994, Modeling Dyanamic Social and Psychological Processes with Fuzzy
Cognitive Maps,Proceeding of the 3rd IEEE Conference on Fuzzy Systems, v3, pp.1873-1877

[6] Digital Library of Science: http://www.gallup.unm.edu/ smarandache/eBooksotherformats.htm

[7] Ghosh, SK \& Akter, MS 2005, 'HANDLOOM INDUSTRY ON THE WAY OFEXTINCTION: AN EMPIRICAL STUDY OVER THE PRE- DOMINANT FACTORS', BRAC University Journal, vol II, no. 2, pp. $1-12$.

[8] Islam, M. K. and Hossain, M. E. 2013, Cost-Benefit Analysis of Handloom Weaving Industry In Kumarkhali Upazila of Kushtia District, Bangladesh, Development Compilation, Vol. 09, No. 01, pp 63-72.

[9] Islam, M. K. and Hossain, M. E. 2015. Determinants of Technical Inefficiency of Handloom Weaving Industry in Kushtia District of Bangladesh: A Tobit Model Approach, Journal of Investment and Management, Vol. 4, No. 4, pp 95-99.

[10] Jaforulla, M. 1999. Production Technology, Elasticity of Substitution and Technical Efficiency of the Handloom Textile Industry of Bangladesh. Applied Economics, 31(4), 437-442.

[11] M. Geethalakshmi and A. Rajkumar 2013, A Systematic Study On Problemsof IT Professionalsin Chennai Using Induced Fuzzy Cognitive Maps (IFCMS), International Journal of Engineering Research \& Technology (IJERT), Vol. 2 Issue 7, 2360-2366

[12] Muhammad Rabiul Islam Liton, Tahmidul Islam, Subrata Saha. 2016 Present Scenario and Future Challenges in Handloom Industry in Bangladesh. Social Sciences. Vol. 5, No. 5, pp. 70-76. doi: 10.11648/j.ss.20160505.12

[13] Rahman, M. M. 2013, Prospectsof Handloom Industries in Pabna, Bangladesh, Global Journal of Management and Business Research Interdisciplinary Volume 13, Issue 5 Version 1.0.

[14] S. Narayanamoorthy and S. Narayanamoorthy 2012 , Adaptation of Induced Fuzzy Cognitive Maps to the Problems Faced by the Power Loom Workers, I.J. Intelligent Systems and Applications, 9, 75-80.

[15] Vasantha Kandasamy W.B and Smarandache Florentin, 2003"Fuzzy Cognitive Maps and Neutrosophic Cognitive Maps", Xiquan, Phoenix. 